\title{
White Book on Physical and Rehabilitation Medicine (PRM) in Europe. Chapter 10. Science and research in PRM: specificities and challenges
}

\author{
European Physical and Rehabilitation Medicine Bodies Alliance
}

\begin{abstract}
A B S T R A C T
In the context of the White Book of Physical and Rehabilitation Medicine (PRM), this paper deals with Research, the future of PRM. PRM students and specialists are mainly involved in biomedical research, investigating the biological processes, the causes of diseases, their medical diagnosis, the evaluation of their consequences on functioning, disability and health and the effects of health interventions at an individual and a societal level.

Most of the current PRM research, often interdisciplinary, originates from applied research which, using existing knowledge, is directed towards specific goals. Translational medical research, research and development, implementation research and clinical impact research are in this field. PRM physicians, mainly master or PhD students, are nowadays increasing their participation in basic research and in pre-clinical trials.

PRM physicians are involved in primary research, which is an original first hand research, but also in secondary research, which is the analysis and interpretation of primary research publications in a field, with a specific methodology.

Secondary research remains an important activity of the UEMS PRM section and it will be the field of the new created Cochrane Rehabilitation. Secondary research with interest for persons with disabilities, will be developed world wide on the basis of evidence based medicine, with the participation of PRM physicians and of all other health and social professionals involved in rehabilitation.

The development of research activities with interest for PRM in Europe is a challenge for the future, which has to be faced now. The European PRM schools, the European master and PhD program with their supporting research and clinical facilities, the European PRM organizations with their websites, the PRM scientific journals and European congresses are a strong basis to develop research activities, together with the development of Cochrane Rehabilitation field and of our cooperation with European high level research facilities, European and international scientific societies in different fields. PRM will be a leader in this field of research.
\end{abstract}

(Cite this article as: European Physical and Rehabilitation Medicine Bodies Alliance. White Book on Physical and Rehabilitation Medicine (PRM) in Europe. Chapter 10. Science and research in PRM: specificities and challenges. Eur J Phys Rehabil Med 2018;54:287-310. DOI: 10.23736/S19739087.18.05154-7)

Key words: Physical and Rehabilitation Medicine - Europe - Biomedical research - Basic research - Translational medical research.

\section{Introduction}

$\mathrm{T}$ he White Book (WB) of Physical and Rehabilitation Medicine (PRM) in Europe is produced by the 4 European PRM Bodies and constitutes the reference book for PRM physicians in Europe. It has multiple values, including to provide a unifying framework for the European Countries, to inform decision-makers at the European and national level, to offer educational material for PRM trainees and physicians and information about PRM to the medical community, other rehabilitation professionals and the public. The WB states the importance of PRM, that is a primary medical specialty. The contents include definitions and concepts of PRM, why rehabilitation is needed by individuals and society, the fundamentals of PRM, history of PRM specialty, structure and activities of PRM organizations in Europe, knowledge and skills of PRM physicians, the clinical field of competence of PRM, the place of PRM specialty in the healthcare system and society, education and continuous professional development of PRM physicians, specificities and challenges of science and research in PRM and challenges and perspectives for the future of PRM.

Science and research in Physical and Rehabilitation Medicine is relatively young, like the specialty, and have some peculiar challenges and specificities. This chapter starts presenting the spectrum of Science in PRM, with the possible organization of research on function- 


\section{COPYRIGHT $^{\circledR} 2018$ EDIZIONI MINERVA MEDICA}

ing and rehabilitation, an overlook on the international congresses topics and PRM journals, and notes about how to strengthen rehabilitation research. A thorough and complete description of the current situation of science and research activities of interest for Physical and Rehabilitation Medicine (PRM) in Europe is then faced, looking and the new possibilities and challenges. The importance of rehabilitation research is defined, and its peculiar methodology due to the problem to bridge the gap between biology and behavior is discussed, facing topics like the relationship between biomedicine and PRM (science is wider than biology), and PRM research (same game, different rules; the two sides of the same coin). The challenges of Evidence Based Medicine in PRM are presented, starting from the current situation and proposals on how to deal with these challenges: means are suggested to improve standards in PRM trials, create sound PRM specific trial designs, and standardize the interventions; finally, the representation of PRM in the "EBM world" and the transfer of scientific knowledge into clinical practice are faced. The last subchapters focus on research training and education.

\section{Spectrum of Science in PRM}

The spectrum of science and research activities in PRM can be described with respect to the curriculum of the UEMS PRM Board, the field of competence of the UEMS PRM Section, the topics and programmes of ESPRM and ISPRM congresses, published in PRM journals 1,2 and listed in the Cochrane Rehabilitation Field. ${ }^{3}$

\section{Organizing human functioning and rehabilitation re- search}

The field of competence for PRM - as described in the conceptual description of PRM 4,5 and represented in the European PRM curriculum ${ }^{6}$ - requires the development of a strong scientific base for a broad range of distinct but related scientific fields. Figure 1 shows a framework of distinct scientific fields ranging from "cell to society" and from the basic to the applied and clinical sciences. 7,8 The core concept underpinning this conceptualization of distinct scientific fields in this framework is the integrative nature of functioning and of the ICF model.

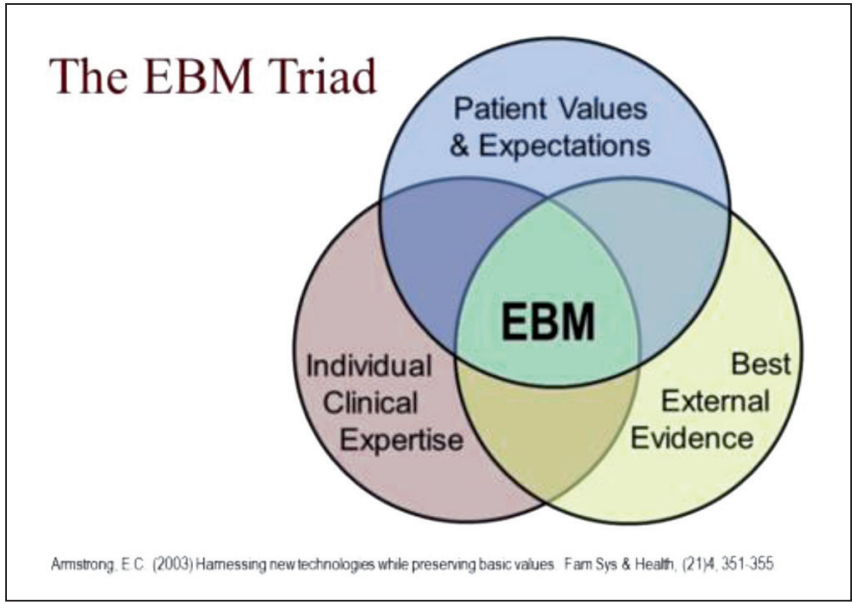

Figure 1.- It depicts the relationship of these 3 components forming the EBM concept.

Congress topic lists: representing the spectrum of current science

The conceptual framework for rehabilitation research shown in Figure 1 is a useful starting point to identify specific scientific topics. A concrete application of this framework is the list of scientific topics for PRM congresses as first developed and continuously updated by ESPRM. ${ }^{9-11}$ Taking up this approach, ISPRM, ${ }^{12}$ has also developed a scientific topic list useful for PRM congresses . ISPRM's scientific topic list provides a comprehensive representation of the spectrum of sciences for PRM. As science is dynamic, the topic list is regularly updated in light of the emergence of new scientific approaches and priorities and the elimination of approaches that are no longer useful. Based on the experiences from the last ISPRM world congresses in Berlin 2015 and Kuala Lumpur in 2016 an updated scientific topic list has been developed. ${ }^{11}$ Appendix A shows the current topic list.

\section{PRM journals in concert}

The publication of scientific studies after a rigorous review by peers is instrumental for the research process to work as well as for the translation of research into practice and evidence-based professional action. ${ }^{13}$ In interaction with societies and congresses, PRM-journals shape the understanding of what constitutes the scientific field of PRM. This enhances the identification of 


\section{COPYRIGHT $^{\circledR} 2018$ EDIZIONI MINERVA MEDICA}

scientists within PRM and the visibility of the scientific field for those outside of PRM. Therefore, scientifically competing PRM journals have a common interest to promote the research process. As did ESPRM. ${ }^{14}$ ISPRM has also developed a web of collaborating PRM journals coordinated by its publications committee. ${ }^{15}$

\section{Strengthening rehabilitation research: shaping the fu- ture of science in PRM}

Human functioning and rehabilitation research has an enormous potential to become a multi-faceted, coherent, research area in which researchers from various disciplines generate and integrate new knowledge, and coordinate efforts to study how to optimize human functioning and the quality of life of people experiencing disability. ${ }^{8,} 16$ The realization of this potential requires the strengthening of research capacity and increased research funding. ${ }^{8}, 17$ Important approaches include the education and training of researchers, development of dedicated research institutions, national and international collaboration networks and interdisciplinary university centers, ${ }^{18}$ as well as the scaling up of existing and creation of new academic training programs in PRM. ${ }^{19}$

A new and important initiative to strengthen the evidence base for PRM is the development of a Cochrane field for Rehabilitation. ${ }^{20}$ Since the optimization of functioning is the goal of rehabilitation, the proper application of the ICF both from a conceptual and methodological perspective is fundamental for this initiative. ${ }^{21}$

These efforts towards strengthening research capacity are important determinants of the future of science in PRM.

Figure 1. Distinct scientific fields in Human Functioning and Rehabilitation Research. The figure illustrates relationships in the process of communication of scientific knowledge between distinct scientific fields. The double arrows indicate that knowledge may be communicated in both directions. The horizontal dimension symbolizes the confluence of knowledge generated by the basic and applied sciences to serve the clinical sciences, and vice versa. The vertical dimension distinguishes the comprehensive perspective based on the integrative model of functioning from the more focused perspective of the biomedical aspects of functioning. Diagonal arrows illustrate the flow of knowledge with respect to both dimensions. Adapted from ${ }^{8} 19$.

\author{
Current situation of science and research \\ activities of interest for Physical \\ and Rehabilitation Medicine (PRM) in Europe, \\ specificities and challenges for the future
}

Scientific and research activities of interest for persons with disabilities is a wider scope which encompasses science and research activities "in" PRM.

The scientific medical research of interest for persons with disabilities or disabling health conditions increases the scientific knowledge which will improve the quality of life of persons with disabilities or disabling health conditions.

\section{The European Union (EU) PRM Section action plan for science in PRM}

The UEMS PRM Section developed an efficient strategy to publish evidence based medicine papers, ${ }^{22,} 23$ including "physical and rehabilitation medicine" in their medical subject heading (MeSH).

There is a strong will of the European PRM organizations to develop science and research activities of interest for PRM in Europe. The European Society of PRM (ESPRM), the PRM Section and Board of the Union of European Medical Specialists (UEMS) and the Academy of Rehabilitation Medicine (AEMR) aim is:

- to support evidence based medicine ${ }^{24}$ by means of research, teaching and training programs, involving medical students, PRM trainees and PRM physicians;

- to facilitate, promote, evaluate and carry out, all research capable of advancing knowledge in the field of persons with chronic disease or disabling health conditions and bringing social, cultural, and economic benefits for society,

- to encourage collaboration between specialists from different disciplines and to develop interdisciplinary programs, which bring together several medical departments as well as other research institutions and industry,

- to bridge gaps between basic and medical research and to translate basic knowledge into better clinical practice,

- to contribute to the promotion and application of research results in the field of persons with disabilities or disabling health conditions,

- to develop scientific information and communication in the field of persons with disabilities or disabling health conditions, 


\section{COPYRIGHT $^{\circledR} 2018$ EDIZIONI MINERVA MEDICA}

- to participate in the analysis of the European scientific orientation and its potential for evolution in order to develop a European research policy in the field of persons with disabilities,

- to facilitate the participation of students and other persons with disabilities or with disabling health conditions in higher education and research activities. ${ }^{25}$

\section{European citizens have a positive attitude toward bio- medical research}

A recent survey for the French national institute for health and medical research (INSERM) including 4000 EU citizens has shown that for $82 \%$ of them, medical research will bring a better life to their children. This underlines how important it is to spread information on PRM research to the citizens.

\section{Financial sources of funding research in PRM are nu- merous and not enough well known}

Despite the confidence for biomedical research of EU citizens, current research funding methods tend to dumb down health care and rehabilitation for disabled people and ageing population. PRM physicians push for a change. ${ }^{26}$

The information on funding opportunities needs to be developed within the PRM specialty, as there are many opportunities in and out of the EU.

EU research programmes such as Horizon 2020 $(\mathrm{H} 2020)^{27}$ offer opportunities to fund Post-Doctoral positions thanks to Marie Sklodowska Curie Actions (including Cofund schemes. ${ }^{28}$ Information support on H2020 is available on the web Euraxess). ${ }^{29}$ Technical support is offered in every European country and in some universities through the national contact points.

Europe and International charitable and nonprofit foundations, are often focused in specific topics, they provide financial supports to research. For example in the field of spinal cord injury, it is the case for Wings for life 30 and Christopher and Dana Reeve foundation. ${ }^{31}$ Max Planck Institutes 32 are other well-known examples.

National research agencies are gathered in "Science Europe" which is an association of European Research Funding Organizations (RFO) ${ }^{33}$ and Research Performing Organizations (RPO), based in Brussels.

Medical schools and universities have dedicated budgets for research activities. ${ }^{34}$ The university research budget composition for all EU countries is rather unbalanced, with government core funding clearly being the main source of income. ${ }^{34}$ PRM Facilities at national or international level are supporting research programs: in France, the UGECAM, ${ }^{35}$ French network of PRM facilities for stroke, in Italy, the Foundation Don Gnocchi, ${ }^{36}$ for Evidence based medicine and Cochrane Rehabilitation and at world level Ramsay, for sport affairs, signed letters of intention to cooperate in research activities with the ESPRM.

The participation of the non-academic sector in EU research $(\mathrm{H} 2020)$ is considered essential. The involvement of industrial participants, of small and mediumsized enterprises (SMEs) in particular, is crucial in maximizing the expected impact of the actions.

\section{The ethical issues and sciences/research activities in PRM}

The protection of human rights and dignity in the specific field of biomedical research is being stricter than it has been in the past. EU guidelines are available, such as the Additional protocol to the convention on Human Rights and Biomedicine, ${ }^{37}$ concerning biomedical research and the protection of animals in research. 38,39

PRM specialists need to pay attention and to avoid conflicts of interest in their research activities. ${ }^{40,41}$ The non-publication of drug trials results raises also ethical issues in research. 42 It is the task of the Accreditation Council for Continuing Medical Education of the UEMS (EACCME) 43 to control the ethical quality of the PRM congresses.

\section{Publications on "Rehabilitation" had a steady growth, during the last decades}

Europe and PRM had a leading role in this evolution. ${ }^{4}$ Publications of PRM during the last 16 years, with a high level of evidence, showed larger multiplication factors compared with those with a low level of evidence. ${ }^{45}$ The publications on rehabilitation are issued not only from PRM specialists but also from researchers in other fields. ${ }^{46}$

\section{The scope of science and research activities in connec- tion with PRM is wide}

The main fields of science and research activities of interest for PRM are numerous. They represent all 


\section{COPYRIGHT $^{\circledR} 2018$ EDIZIONI MINERVA MEDICA}

components and domains/chapters of the International Classification on Diseases and of the International Classification of Functioning, Disability and Health. ${ }^{47}$

The main fields of science and research activities of interest for PRM are linked to the domains of research organized at European research level in the following disciplines: 48

- neurosciences, with all the scientific and medical fields dealing with the central and peripheral nervous system: its normal and pathological formation, development, functioning and ageing; ${ }^{49}$

- physiology, physiopathology, metabolism and nutrition, cardio-vascular system, respiratory system, bones and joints;

- public health, including epidemiology, biostatistics, economy and sociology applied in the health field,

- health technologies, in particular imaging, development of drugs, biotechnology, bioengineering, interventional techniques for medical diagnosis and treatment;

- cell biology, development and evolution;

- genetics, genomics and bioinformatics.

\section{The modalities of scientific and research activities of in- terest for PRM are numerous}

The scientific research of interest for PRM is mainly in the field of biomedical research which is the broad area of science that involves the investigation of the biological process, the causes of diseases, their medical diagnosis, the evaluation of their consequences on functioning, disability and health, at an individual and a societal level. The Alliance for Biomedical Research in Europe 50 is involved in this field.

PRM biomedical research is mainly represented by clinical research \& clinical trials.

PRM researchers are more often than in the past involved in:

- inter disciplinary research programs, within teams including other disciplines or bodies of specialized knowledge. The Human Brain Project is an interdisciplinary program co-funded by the EU;51

- applied research programs, directed towards specific goals and discoveries, such as the development of a new medication, a new medical device, or a new rehabilitation procedure. They are using existing knowledge (gained from basic research) and methodically expand- ing this knowledge to address the specific rehabilitation problems; ${ }^{46}$

- pre-clinical trials, involving experiment in cells and in non-human animal models; 52

- translational research, research and development, from the laboratory to the patient's bed and home, are the aim of the European Advanced Translational Research Infrastructure in Medicine 53,54 but even the most promising findings of basic research take a long time to translate into clinical experimentation, and adoption in clinical practice is rare; 55

- implementation research (IR), evaluate rehabilitation health interventions in "real world" settings; 56

- information and communication technologies (ICT) robotics and devices research are cited in many of the EU research programs "ICT H2020" areas in order to tackle societal challenges;

- basic research programs, in which PRM physicians, are sometimes involved during their Master, $\mathrm{PhD}$ or Post Doc studies.

\section{The settings of scientific and research activities in PRM are numerous}

The number of academic professors in PRM is increasing in some EU countries, leading to the development of clinical research activities in their teams.

The number of PRM facilities with clinical research activities is also increasing, some having conventions with universities and/or EU PRM bodies such as the European society of PRM (Foundation Don Gnocchi, ${ }^{36}$ UGECAM, ${ }^{35}$ Ramsay Health Care). ${ }^{57}$

Research teams, departments, laboratories and institutes, are developing inter disciplinary research activities, from basic to applied research in one or more specific fields. ${ }^{58}$ They are headed by scientists and/or PRM specialists. They are often part of national or international networks focused in a field.

THE ELECTRONIC SUPPORT FOR COMMUNICATION AND INFORMATION ON THE PRM SCIENTIFIC AND RESEARCH ACTIVITIES IS MAINLY BASED ON THE WEBSITES OF THE EUROPEAN PRM ORGANIZATIONS

The European Academy of Rehabilitation Medicine, ${ }^{59}$ the UEMS PRM Section and Board 60 and the ESPRM spread scientific information all over the world. Other scientific websites are available in specific fields, 


\section{COPYRIGHT $^{\circledR} 2018$ EDIZIONI MINERVA MEDICA}

for example for stroke with the "evidence based review of stroke rehabilitation". 61

\section{ESPRM congresses and the European/Euromediterra- nean PRM schools are successful}

PRM physicians participate both in PRM congresses or in topic focused congresses. Topics can be pathologies such as stroke, spinal cord lesions, functional disorders such as swallowing, mental disorders, health interventions, such as ultrasound diagnosis, joint injections etc.

The congresses of the European Society of PRM are held every two years. They have gathered up to 2400 participants. The main PRM European organizations, PRM Section and Board of UEMS and European Academy of Rehabilitation Medicine participate in these congresses. Research, Education, Professional Practice, Field of Competence and Ethics are the main topics of these congresses. All the fields of PRM are reviewed.

Two new events have been held during the ESPRM congress in 2016, the "Labs' Day session" and the "My Rehab Thesis in 180 seconds" (MRT180). They will be held again in the next congress in Vilnius May 2018. International and EU national congresses of PRM are listed on the website of the ESPRM in the calendar of events. ${ }^{62}$

Three international PRM schools are held every year. They spread evidence based knowledge and present recent research activities to PRM trainees (the Euro Mediterranean Rehabilitation Summer School Haim Ring in Syracuse of Italy, the Intensive Teaching Programme Cofemer Ajmer Sofmer and the European School Marseille of France on Motor Disabilities). A new European school for PRM trainees will be available in Vilnius 2018.

European and International congresses focusing on specific topics, such as Pain, ageing persons, Stroke, SCI, ENMG etc, welcome PRM physicians and all the professionals interested in the field. ESPRM has set up special interest scientific committees ${ }^{63}$ which are the link between the ESPRM, scientific societies and all professionals focused on a topic, with dedicated congresses and scientific journals.

\section{PRM scientific journals are very active}

As for the oral communications in congresses, the written scientific communication from PRM physicians can be submitted either to PRM journals or to other scientific journals specialized in a topic. The emergence and development of open access has been and still is a great challenge, both for the authors and the readers. It is not always easy to download the full paper.

The European Journal of PRM is the official journal of the ESPRM and of the UEMS Section of PRM. ${ }^{64}$

The Journal of Rehabilitation Medicine is the official journal of the European Academy of Rehabilitation Medicine and of the UEMS European Board of PRM. ${ }^{65}$

The other European PRM journals have been listed in a publication. ${ }^{66}$

\section{The Cochrane Rehabilitation field is a chance for the future of Rehabilitation}

Scientific literature review deals with secondary sources published in academic, peer reviewed journals and follow a methodology for the analysis of the available data (key words, MeSH, search engines such as PubMed). The scientific literature review provides the current state of the medical scientific knowledge in a field. For stroke, an example is the evidence-based review on stroke rehabilitation. ${ }^{61}$

Starting from the evidence based committee of the ESPRM, ${ }^{63}$ under the guidance of Professor Stefano Negrini and co-workers (Carlotte Kiekens, Elena Ilieva and Frane Grubisic) PRM EU organizations and other international PRM organizations have been welcomed by Cochrane in a new "Cochrane Rehabilitation Field" 67 based on the fields of competence of PRM.

Cochrane Rehabilitation Field is aimed to ensure that all rehabilitation professionals can apply evidence based clinical practice, combining the best available evidence as gathered by high quality Cochrane systematic reviews, with their own clinical expertise and the values of patients. Our vision is a world where decision makers will be able to take decisions according to the best and most appropriate evidence in this specific field. Cochrane Rehabilitation Field wants to improve the methods for evidence synthesis, to make them coherent with the needs of people with disabilities or experiencing disability and the daily clinical practice in rehabilitation.

\section{Challenges for the future}

MAIN CHALLENGES ARE INFLUENCING RESEARCH ACTIVITIES IN PRM

- an ethical one, with the United Nations rights of persons with disabilities ${ }^{6}$ for equal access to medicine 


\section{COPYRIGHT $^{\circledR} 2018$ EDIZIONI MINERVA MEDICA}

and rehabilitation, to quality of life in the society;

- a public health one, with the demography of chronic diseases, the development of ageing-related impairments 43 together with the societal impact of research; 69

- a scientific one, with the development of the medical scientific knowledge in all fields; ${ }^{6} 9$

- a technological one, demonstrated by the increasing use of imaging and research laboratories with interdisciplinary activities, including clinicians. ${ }^{70}$

With also the development of e-medicine (database, search engines, eBooks) and of robotics. ${ }^{71,72}$

- an economic one, with the increase of the health expenses at state level and the cost of research. The funding of research in EU is not one of the highest in the world, it varies from a country member to the other one. In 2020,3\% of the EU's gross domestic product (GDP) should be invested in research and development (R\&D). Health and ageing are among the main topics of research for EU programs (Europa EU).

\section{PRM IN EUROPE IS WILLING TO INCREASE THE NUMBER OF RESEARCHERS AND TO ELEVATE THE QUALITY OF RE- SEARCH}

Education to research will be a key issue all along the medical studies, for undergraduate students, for postgraduate PRM trainees with access to the master and $\mathrm{PhD}$ programs, the post-doctoral programs.

Undergraduate programs in the medical schools, should include critical reading 73 and biostatistics. Postgraduate programs in the faculties of medicine, should support the development of the scientific thinking with journals club, ${ }^{74}$ master programs with initiation to research during the first year. The topics are often: systematic reviews, medical literature databases to search, bibliography management, methods in therapeutic evaluation, principles of epidemiology, advanced biostatistics, critical thinking, training in a laboratory etc.

Articles, teaching and training programs, for scientific oral and written communication, either for academic meetings, interdisciplinary cooperation or for public oriented communication, are now available. ${ }^{75-77}$

During the ESPRM congress is organized a presentation in three minutes of research works from $\mathrm{PhD}$ students, so called, "My rehab thesis in $180 \mathrm{sec}$ " which is a way to present a research project in rehabilitation, in a short time using simple word, as for the Three Minutes Thesis. ${ }^{78}$

The Board/ESPRM school: during the next congress in Vilnius will be organized for the first time a school for PRM trainees which will cover the whole curriculum of the specialty. It will benefit from special sessions of the three schools for European PRM trainees which are organized every year, the Euro Mediterranean Rehabilitation summer school in Syracuse, the Intensive teaching program COFEMER, SOFMER, AJMER (during the French SOFMER congresses) and the European School Marseille on motor disabilities. Lessons on the main topics of our specialty will be held by experts in the field.

The access of PRM masters, PhD students and Postdocs to the EU research programs, such as H2020 is encouraged by the ESPRM. PhD disabled students could benefit from dedicated funding. ${ }^{79}$

The European PRM organizations are currently involved and willing to do more, in developing science and research activities of interest for the disabled persons. They are convinced that the future of PRM is research!

\section{Importance of rehabilitation research in establishing needs and the value of both current and new approaches to rehabilitation}

PRM has fully endorsed the principles of evidencebased medicine and research in PRM has made great progress during the last three decades. Whereas the physiological mechanisms of action of physical modalities of function have traditionally been central to scientific interest during the last decades of the $20^{\text {th }}$ century, an increasing number of prospective trials have been performed, in which the clinical efficacy of rehabilitation in many diseases, such as low back pain, stroke, brain and spinal cord injury, ${ }^{78-80}$ rheumatoid arthritis, cardiovascular, pulmonary and metabolic disorders, has been tested. For most conditions, meta-analyses and (inter)national guidelines and clinical pathways are available and provide levels of evidence for distinctive interventions.

\section{Relevance of research}

The specialty aims to foster an increased interest and involvement in research in rehabilitation. This has re- 


\section{COPYRIGHT $^{\circledR} 2018$ EDIZIONI MINERVA MEDICA}

sulted in an increasing number of publications in high impact international scientific journals. Its vision is that research is necessary to understand the basic processes of rehabilitation such as how individuals acquire new skills, and how the tissues of the body (for example, the muscles, or neuronal pathways in the central nervous system) can recover from or adapt to the effects of trauma or disease. Research can also delineate the incidence and prevalence of disabilities, and identify the determinants both of recovery and of the capacity to change, to acquire new skills, and to respond to rehabilitation.

New technologies emerge and should be adapted for use by people with disabilities. Rehabilitation technology is one of the most important and promising research fields today and in the future. Tissue engineering and other modern technologies are contributing to this field. The costs of health care and of rehabilitation services will increase and politicians will force health care providers to restrict their expenses and show that they organize this care efficiently. PRM specialty is a reliable partner in the discussion with patients, politicians, ministries of health and insurance companies, as it has the capacity to base its arguments on sound evidence in the public arena, which only research can provide.

\section{Methodology of research in Physical and Rehabilitation Medicine: bridging the gap between biology and be- haviour. Biomedicine and Physical and Rehabilita- tion Medicine: science is wider than biology}

It seems that in Medicine there are two (not mutually exclusive) models: the one linked to Bio-medicine, and the other representing Clinical Medicine, including Physical and Rehabilitation Medicine (PRM). ${ }^{80}$ What is respectively meant here by the terms "Bio-medicine" and "Clinical Medicine" is later detailed.

The dominant model is the bio-medical one, just a mild variant of the scientific paradigm, dating back to the $17^{\text {th }}$ century, which is reductionist and deterministic. In order to understand the whole, the parts must be observed (reductionism, as in anatomy), and general invariant laws regulating the interactions across parts must be discovered (determinism, as in physiology). In principle, any "phenomenon" (what is appearing, according to the Greek etymology) is potentially predictable because it reflects physical laws. According to the biomedical model, the unit of observation is not the person: it is a part of the person (no matter whether organ or molecule). Let's imagine a gradient running from molecules to the person, and then to populations. At the "population" extreme, the field of epidemiology, the core topic is again not the person: persons appear as replicable individuals, whose properties can be summarized by measures of their central tendency (means, medians).

Conversely, the Clinical Medicine model -apparently in contrast with the bio-medical model - entitles the single person as a whole as its primary interest, and it aims at applying a person-centered healthcare (including shared decision-making): its relationship with social aspects is inseparable. In other words, the disciplines belonging to Clinical Medicine - such as PRM - are not bounded to any specific body 'parts' and encompass the patient-environment interaction (including the patient-therapist relationship, and optimal gathering of patient's preferences, values, and goals). The person-toperson relationship (one of "cure and care") is forcibly unique, sensitive to emotional and cultural factors, and in line with the growth of the so-called bio-psycho-social model of medicine. For sure, the unitary 'phenomenon' (the ill person and his/her signs and symptoms) conceals troubles in his/her biological parts, yet the patient's behavior is also characterized by freedom and thus unpredictability. Not so clear understanding and 'repairing' the ill person is the specific goal of Clinical Medicine, yet it requires an approach wider than paradigm underlying biological sciences.

This chapter asserts the scientific status of PRM, an essentially-clinical medical specialty, by highlighting the specificity of its research paradigms. PRM aims to foster an increased interest and involvement in research in rehabilitation because research is necessary to understand the basic processes of rehabilitation, such as for example - how individuals acquire new skills, or how different tissues in the body (e.g. muscles, or neural pathways) can recover from or adapt to the effects of trauma or disease. Research can also delineate the incidence and prevalence of disabilities and disabling health conditions, and new rehabilitation technologies emerge and should be adapted for use by people with disabilities. Moreover, the cost of healthcare and rehabilitation services is constantly increasing, and politicians force healthcare providers to restrict their expenses and to show that they efficiently organize this care. 


\section{COPYRIGHT $^{\circledR} 2018$ EDIZIONI MINERVA MEDICA}

PRM is a reliable partner in the discussion with patients, politicians, ministries of health, and insurance companies, to the extent that it has the capacity to base its arguments on sound evidence in the public arena, which only research can provide.

\section{PRM research: same game, different rules}

PRM has fully endorsed the principles of evidencebased medicine, and research in PRM has made great progress during the last decades. ${ }^{81,} 82$ In our field, this process of knowledge and decision-making usually tries to include three essential points: best scientific evidence, clinical expertise, and need and wishes of patients. This process is complex because PRM has its roots in biology (deep knowledge of human anatomy, physiology, and various pathologies), but also spans to behavioral sciences. ${ }^{83}$ Such a double nature of PRM is a source of charm, yet it requires high versatility in performing research, depending on the location of the research topic along the biology-behavior continuum. Studying the effect of shock-waves on soft tissues does not require the same method suitable for studying dependence in daily life, attention deficits, pain, fatigue, or social interaction, in individuals. The latter variables relate to the person as a whole; the object of observation is a unitary subject interacting with the observer. For these reasons, rehabilitation research does not sit comfortably with some standard approaches to basic science and biomedical research interventions.

Moreover, behavioral research is often considered according to reductionist-deterministic model - to be "qualitative" and flawed by "subjectivity". Conversely, there are no reasons why human behaviors and perceptions should not be amenable to rigorous scientific investigation. However, instruments and methods must be suitable to the study goals.

In short, the key differences between the biological (Bio-medicine) and the behavioral (Clinical Medicine) research paradigms relate to: 1) variables analyzed; 2) statistical methods, and 3) trial designs. ${ }^{80}$

\section{PRM research: the two sides of the same coin}

In summary, PRM research uses methods coming from both the biomedical field and clinical and behavioral sciences, in order to generate useful high-quality evidence. The biomedical methods are strong and wellknown, based on established disciplines, spanning from biomechanics to neurophysiology, from biochemistry to epidemiology. Conversely, methods coming from clinical and behavioral sciences need to be reinforced by specific research designs, and proudly claimed for as a key source of scientific identity of PRM. A wider diffusion of these designs may also help to promote communication and knowledge translation with other nonmedical professionals, who also work with people with disability.

Even the name 'Physical and Rehabilitation Medicine' needs some reflection: 89 is the adjective 'physical' redundant or restrictive? Not at all, if this term is linked to its Greek etymology (physis means nature, the universe to which Mankind also belongs), as in other terms, such as "physician" or "physiology". In this sense, 'physical' indicates a type of medicine "practiced from the outer world on the person as a whole' (in agreement with the biopsychosocial model of medicine). On the other hand, 'rehabilitation' indicates the goal, which is aiming at restoring a person's ability (i.e. the best possible interaction with the outer world). The intersection between the most various 'physical' means and the 'rehabilitation' goal is the cultural pillar of PRM. However, government agencies and providers often seek evidence of the cost-effectiveness of rehabilitation and usually require the services as a whole to be evaluated, because a wide range of different techniques has to be available to the treating team in order to meet the different needs of individuals in any group of patients. This really is the nub of the problem, as PRM practice produces results through a series of, or the interplay between, a number of interventions. Demonstrating the impact of a single rehabilitation intervention is not consistent with 'real life', and while it is essential for identifying effective individual procedures to be included in a rehabilitation program, it cannot in itself effectively evaluate the program as a whole. Unlike biomedical research, where a single treatment is usually tested on many individuals, in PRM several treatments are often applied to a single individual. The unit of treatment is thus the 'program' as a whole. This needs not to be arbitrary. It should follow the logic of rigorous decision-tree algorithms: different treatments are assigned to single individuals, yet according to reproducible rules. To sum up, in order to produce practice guidelines, it is important for PRM to 


\section{COPYRIGHT $^{\circledR} 2018$ EDIZIONI MINERVA MEDICA}

recognize also the value of dynamic learning (through the application of the so called 'Plan-Do-Study-Act' cycle), and move in the direction of systems knowledge, agreeing on the use of common sets of methods and measures for developing and disseminating evidence. ${ }^{88}$ Specific research (also borrowed from different disciplines, including social sciences, and then optimized according to PRM research needs) using dedicated rules and skills should thus be encouraged from the cultural, political and financial point of view, and become explicit components for building a PRM curriculum.

\section{Challenges of evidence based medicine in PRM}

"Absence of evidence is not evidence of absence". .90 This provocative statement represents one side of the coin in an ongoing debate on evidence based medicine (EBM). On a closer look it means that the absence of external evidence for individual forms of therapies is not proof of their ineffectiveness.

So what is the concept of EBM?

According to the pioneers of EBM Gordon Guyatt and David Sackett, co-founders of the first international EBM working group ("evidence based medicine working group"), EBM is "the conscientious, explicit, and judicious use of current best evidence in making decisions about the care of individual patients." The practice of evidence-based medicine means integrating individual clinical expertise and patient values with the best available external evidence from systematic research. ${ }^{91}$ Sackett demonstrated how these three areas of EBM form the valuation of therapy methods and how they have to be evaluated for each individual patient (Figure 1). ${ }^{24}$

\section{Best external evidence}

EBM has promulgated a hierarchy of best research evidence and ranks them according to the strength of their freedom from the various biases that beset medical research. The quality of external evidence may be judged on different levels:

- single studies;

- systematic reviews and meta-analysis;

- recommendations and guidelines.

For each of these levels, evaluation tools and methods have been elaborated. To judge the quality of a single study, checklists of items for reporting trials have been published, assisting scientists and clinicians with evaluation, e.g. the Physiotherapy Evidence Database (PEDro) Scale.

The PEDro Scale is based on the Delphi list developed by Verhagen et al. at the Department of Epidemiology, University of Maastricht. ${ }^{92}$ It is a criteria list for quality assessment of randomised clinical trials for conducting systematic reviews developed by Delphi consensus. ${ }^{93,94}$

Alternatively, the Cochrane Collaboration promotes tools to evaluate the risk of bias in single studies. These evaluation tools contribute, among others like outcomes etc. to formulate systematic reviews and meta-analyses. Nevertheless, systematic reviews do not grade the overall quality of evidence across outcomes. Because systematic reviews do not - or at least should not - make recommendations, the quality of evidence is rated only for each outcome separately.

Caution should therefore comprise simple grading systems rating external evidence from 1 to 4 like the Oxford levels of evidence.

Finally, to get an overview of the entire body of evidence on a specific topic, results may be summarized and valued by different scoring systems. This is a task for guideline panels which have to determine the overall quality of evidence across all the critical outcomes essential to a recommendation they make. Guideline panels provide a single grade of quality of evidence for every recommendation, but the strength of a recommendation usually depends on evidence regarding not just one, but a number of patient-important outcomes and on the quality of evidence for each of these outcomes. This complex and multidimensional evaluation requires specific evaluation tools.

A widely used methodology that is also used by the Cochrane Collaboration is the Grading of Recommendations, Assessment, Development, and Evaluation (GRADE) system.95 This tool was developed for working groups of experts and scientific societies to evaluate the current evidence and formulate recommendations and suggestions for clinical practice. 96

Outcomes in the GRADE system are the strength of recommendations and the quality of evidence.

Quality of evidence is classified as

- High: confidence that the true effect lies close to that of the estimate of the effect

- Moderate: there is moderate confidence in the ef- 


\section{COPYRIGHT $^{\circledR} 2018$ EDIZIONI MINERVA MEDICA}

fect estimate. The true effect is likely to be close to the estimate of the effect, but there is a possibility that it is substantially different

- Low: confidence in the effect estimate is limited. The true effect may be substantially different from the estimate of the effect.

- Very low: very little confidence in the effect estimate. The true effect is likely to be substantially different from the estimate of effect.

Strength of recommendations means: the strength of a recommendation reflects the extent to which a guideline panel is confident that desirable effects of an intervention outweigh undesirable effects, or vice versa, across the range of patients for whom the recommendation is intended.

The GRADE system suggests using the terms strong and weak recommendations.

A strong recommendation is one for which the guideline panel is confident that the desirable effects of an intervention outweigh its undesirable effects (strong recommendation for an intervention) or that the undesirable effects of an intervention outweigh its desirable effects (strong recommendation against an intervention). Note: Strong recommendations are not necessarily high priority recommendations. A strong recommendation implies that most or all individuals will be best served by the recommended course of action.

A weak recommendation is one for which the desirable effects probably outweigh the undesirable effects (weak recommendation for an intervention) or undesirable effects probably outweigh the desirable effects (weak recommendation against an intervention) but appreciable uncertainty exists.

A weak recommendation implies that not all individuals will be best served by the recommended course of action. There is a need to consider more carefully than usual the individual patient's circumstances, preferences, and values. When there are weak recommendations caregivers need to allocate more time to share decision making, making sure that they clearly and comprehensively explain the potential benefits and harms to a patient.

Consequently, the GRADE system does not automatically rank RCT higher than observational studies (like the Oxford system would do). For instance, RCTs can be downgraded because of risk of bias, indirectness, imprecision and publication bias. However, observational studies can be upgraded because of large effects, dose response and confounders.

It is of utmost importance that the GRADE system states that:

- clinicians, patients, third-party payers, institutional review committees, other stakeholders, or the courts should never view recommendations as dictates. Even strong recommendations based on high-quality evidence will not apply to all circumstances and all patients;

- users of guidelines may reasonably conclude that following some strong recommendations based on the high quality evidence will be a mistake for some patients. No clinical practice guideline or recommendation can take into account all of the often compelling unique features of individual patients and clinical circumstances. Thus, nobody charged with evaluating clinician's actions, should attempt to apply recommendations by rote or in a blanket fashion.

\section{Situation of PRM}

There is no doubt about the importance and necessity of Evidence Based Medicine (EBM) in positioning and developing the specialty of PRM. In the past, trials of high quality, especially randomized controlled trials were sparse, leading to predominance of clinical experience and patient values. Especially in PRM, trials on a high scientific level bear a lot of challenges and controversies and are therefore difficult to execute.

\section{Challenges of PRM}

The nature of the PRM specialty is fundamentally different from others, e.g. internal medicine or even surgery. Administering drugs to patients is relatively easy to standardize, both in dosage and compliance, and blinding can be done adequately.

Also surgery adheres to highly standardized procedures in reproducible settings. Recently, researchers have even implemented sham surgery to control for treatment effects (Arthroscopic partial meniscectomy versus sham surgery for a degenerative meniscal tear.).

The specialty of PRM adopted the ICF as concept for its clinical work (not applicable for medical diagnosis, refer publications on cases with imagery, ultrasounds etc.). This implies a number of influential variables, from body structures and function up to personal and 


\section{COPYRIGHT $^{\circledR} 2018$ EDIZIONI MINERVA MEDICA}

environmental factors. This concept reflects patient's reality but counterweighs standardization of procedures.

Many PRM interventions are heterogeneous in its application, dosage (intensity, duration, frequency of application) and individual preference, both by clinicians and patients. Fundamental experimental data on treatment effects are sparse. This makes it difficult to design an effective placebo method if the underlying mechanism is not clear. Often, up to date and scientifically sound knowledge on physical modalities comes from other specialties. For example, research on "sonoporation" (ultrasound-driven transport of drugs through the skin) is currently strongly promoted by oncological scientists. This scientific approach provides scientific models, which can be easily adopted for PRM purposes, e.g. delivering drugs in musculoskeletal problems.

The number of researchers is relatively small, although rapidly growing.

Funding of trials, especially of basic experimental research is too little and cannot be compared to pharmaceutically driven trials.

A major challenge in conducting high quality clinical trials is the understanding of placebo in our specialty. Fregni, Imamura and others published a fundamental paper as a result of the International Placebo Symposium Working Group on recommendations and challenges for placebo control in PRM.97 They identified several challenges of placebo use in PRM clinical trials. Some of them are reflecting the framework, concept and working principles of the specialty.

- Development of placebo and sham devices

- Lack of standards in PRM therapies

- Treatment heterogeneity due to therapist skill differences

- Issues with adequate masking

- Personal interaction between therapist and patient

- Personal beliefs, previous experience and motivation

- Small effect sizes

- Long follow-up

- Lack of training to conduct clinical research

- Use of medical devices.

Furthermore, some clinical conditions, simply do not allow the use of placebo or sham device. These conditions comprise trials testing hydrotherapeutic interventions, effectiveness of lower limb prosthesis, or use of sham-orthosis for drop foot.
Another challenge is the use of combination therapies. In clinical practice PRM therapies are often combined with each other or are prescribed in combination with drug therapy. Because there are a lot of possibilities to combine therapies, it was, in the past, not possible to design clinical trials of all possible combinations. These designs make the interpretation of each single treatment used very difficult. The question often remains if the used interventions influence each other. Furthermore, PRM physicians, more than in other specialties, are often dealing with multi-morbid patients. For obvious reasons designing and executing adequate studies with suitable participants can be very challenging.

Many of the above mentioned reasons contribute to the fact that inadequate study design, small number of participants, different parallel group designs and insufficient blinding and placebos led, among others, to poorer trial quality, especially compared to pharmacologic trials. Subsequently, studies performed in the past in our field were often not included in meta-analyses and consequently many of our specific treatments lack higher grade of evidence. As a consequence, this leads to impaired recognition from clinicians and researchers in the scientific community and an underrepresentation in EBM textbooks. In times of increasing financial shortcuts there may be tendencies to misuse this "lack of evidence" by stakeholders of healthcare systems to reduce costs. Out of this attitude, considerable pressure by health care may occur not to fund diagnostic and therapeutic procedures in the field of PRM.

Besides methodological shortcomings in PRM studies, the difference between organ based medicine and PRM is also promoted by the fact that the former is highly influenced by industrial interests, which may explain those different levels of evidence-based knowledge. ${ }^{98}$

\section{How to deal with these challenges}

Fortunately, in recent decades strong efforts were undertaken to increase the number of high quality studies and RCTs in the field. Progress was made in design and statistical methodology. Also inclusion and exclusion criteria in reviews influence results. One example of the influence of the number of high quality studies influencing meta-analysis outcomes is the recent second update of a Cochrane review on TENS in acute pain. In the past years data were insufficient to support the effectiveness of TENS 


\section{COPYRIGHT $^{\circledR} 2018$ EDIZIONI MINERVA MEDICA}

treatments in acute pain. By increasing the number of high quality RCTs and by excluding studies with insufficient dosage of TENS the Cochrane conclusion was upgraded to a tentative recommendation for the use of TENS. ${ }^{9}$

\section{Improve standards in PRM trials}

The main road to improve the appreciation of PRM is improving clinical research in quality and quantity, both on the level of basic science in the laboratories and on the clinical level.

The latter nowadays makes the conduct of high quality clinical trials such as the placebo or sham-controlled randomized clinical trials mandatory. Only these trials have the chance to be included in meta-analysis, e.g. Cochrane reviews, that provides the basis of recommendations and guidelines. This is important because clinical recommendations and guidelines influence medical education ensuring the implementation in daily clinical routine.

\section{Create sound PRM specific trial designs}

Basically, one should not be misguided transferring all the principles of high quality trials in pharmacotherapy directly into the field of PRM. Several differences have to be taken into account requesting a specific concept of double-blinded randomized controlled trials (RCT) in the field of PRM. Generally, scientists made efforts elaborating recommendations recognizing the difference between pharmacologic and non-pharmacologic trials and facilitating recommendations conducting the latter. ${ }^{100}$ This group also gives recommendations for design and manuscript preparation taking into account the nature of non-pharmacologic trials.

\section{Standardize interventions}

Interventions in PRM are not often homogeneous. Responsible for this are lack of basic scientific data, preferences of patients and clinicians, recommendations of manufacturers and others. As example for neuromuscular electrical stimulation of extensor muscles in osteoarthrosis of the knee, a variety in amplitude, frequency, electrode size and location are published. Only few reviews up to date made efforts to determine parameters generating best clinical treatment effects. ${ }^{101}$ This standardization is necessary to conduct trials with comparable interventions.
Recommendations and guidelines from adjacent scientific societies can be adopted for standardization of treatment interventions. For example, the American Heart Association and the American College of Sports Medicine published distinct recommendations for administering exercise therapy to different groups of patients. ${ }^{102}$ These guidelines have to be adopted by PRM as standard procedures.

\section{Representation of PRM in the "EBM world"}

Up to now the specialty of PRM was not distinctly and uniquely represented in various databases of EBM. One has to look for "physiotherapy", "physical therapy", rehabilitation", or "exercise" to find EBM data in our field. The launch of Cochrane PRM is a major step to overcome this problem. Within the Cochrane Fields and Networks, Cochrane Rehabilitation Field was established in 2016 and can serve as a Field, whose aim is to function as a bridge between the stakeholders and Cochrane. ${ }^{1}$ The available evidence with regard to rehabilitation will be disseminated to the different concerned health professionals by means of educational, communication or publication strategies. Methodological issues will be tackled.

\section{Transfer of scientific knowledge into clinical practice}

After this knowledge translation, it is crucial to transfer evidence and guidelines into clinical practice. Especially in PRM, this does not only comprise PRM physicians but furthermore the entire rehabilitation team. This underlines the importance of the PRM specialist as a leader of the therapeutic team who consequently promotes EBM based procedures in the therapeutic and rehabilitative process. This requests adequate communication skills to convince all team members and implement it in daily routine.

It may be supportive to establish national working groups to facilitate this process.

\section{Conclusion}

EBM is part of modern medicine and thus also part of PRM. Nevertheless, we have to be aware that EBM is often reduced to external evidence based on meta-analysis and randomized, placebo controlled trials. PRM trials cannot be compared to pharmaceutical ones. Corre- 


\section{COPYRIGHT $^{\odot} 2018$ EDIZIONI MINERVA MEDICA}

EUROPEAN PHYSICAL AND REHABILITATION MEDICINE BODIES ALLIANCE SCIENCE AND RESEARCH IN PRM: SPECIFICITIES AND CHALLENGES

TABLE I.

Table IA summarizes the main differences. The "variables" related to the person are so-called "latent" variables or "traits". 84 They cannot be entirely observed, they are not 'manifest': independence, pain, fatigue, balance, language skills and the like are hidden in the person. Their presence and their quantity can only be inferred from representative observable behaviours. Typically, these are selected and listed as items in cumulative questionnaires or scales. The amount of the variable is reflected by the ordinal, integer scores (also said "raw scores"; e.g. an independence score achieved on the Functional Independence Measure scale). The construction and validation of outcome measures is at the core of PRM research methodology, not less than biomechanical and neurophysiological methods. This scientific field is known as psychometrics, due to its origin, in the early $20^{\text {th }}$ century, from the study of 'psychological' phenomena; however, the term 'person-metrics' should be preferred.

Table IB summarizes the specificity of statistical analyses aiming at measuring "latent variables". These are properties "hidden" in the person (such as knowledge, perceptions, capacities, mood and the like), which can only be inferred from representative behaviours. Once the variable of interest is defined, scale construction becomes a priority. The methods of construction and validation of these tools are complex and imply not only clinical and mathematical skills, but also deep epistemic reflection (in order to create scales that reflect real, existing — albeit hidden — variables). A key point is the validity of raw scores as measures: indeed, raw scores given to items (e.g. 0/1: absence/presence; 0/1/2: no/moderate/intense; etc.) are just counts of observations (e.g. how many times it happened that 0 rather than 1 was observed, etc.) but they do not tell us "how much more" of the variable does "presence" mean compared to "absence", nor they tell us "how much more" of the variable does "moderate" mean compared to "absent", and how much "less" does it mean compared to "intense". Sophisticated mathematical modelling is needed (e.g. the Rasch analysis), deeply nested in PRM culture 85 not only in educational and sociological research paradigms.

Once the appropriate measures of the proper variables have been achieved, conventional statistics come to play. Oversimplifying the topic, statistical models mainly try to answer the critical question: is a given difference (between groups, before-after treatment, etc.) observable by chance alone? In conventional "bio-medical" statistics a significance level is often the final criterion: if that difference can be observed by chance beyond an arbitrary percent of the potential replications of the same measurement (usually, $5 \%$, i.e. $\mathrm{P}=0.05$ ), results are said to be "non-significant". This Neyman-Pearson hypothesis-rejection paradigm is best applied to indexes of central tendency in populations (usually means and medians) and gives protection against false-positive results (i.e. those that may come from pure chance). But, first the substantial protection against false-positive findings paradoxically decreases, the more the number of observations increase: in large samples irrelevant differences can easily become statistically "significant" despite being marginal or useless in clinical practice. Second, the more you are protected (which is the case with small samples), the more true-positive results will be also discarded. Therefore, an increasing interest can be observed for the estimation of "power" (the probability for detecting true-positive results) and of the sample 'size', and ultimately of the clinical 'importance' of the effects, together with their p-based significance (Table IB).

Along the same line, other sophisticate statistical approaches are available, and their use is growing in PRM literature, in order to understand changes in individuals (and not just in populations). An example is the search for: a) the "minimal detectable change" (MDC, also called "minimal real difference"), i.e. the smallest change (e.g. before and after a treatment) that likely reflects true change rather than measurement error alone, in single individuals. Its value is linked with reproducibility indexes, and distribution-based statistical models; and b) the "minimal clinically important difference" (MCID), that represents the smallest measurement change to be considered meaningful according to clinical criteria (linked to an external judgement, implying anchorbased statistical models), and must be equivalent to or higher than the MDC.

Table IC illustrates the third and last rule of the game to be considered, i.e. the trial design. Again oversimplifying this scientific topic, one can say that trial design aims at estimating the strength of causal relationship between treatment and outcome. The more a causal inference is sustainable, the more an observed outcome can be said to be a result. Statistics tells you whether the outcome is not incidental; trial design supports your claim that the cause was the one you supposed. In other words, the trial design strives to solve the unavoidable "third variable explanation problem" (a type of confounding in which a third' variable -actually, one or many more, often unsuspected- leads to a spurious causal relationship between two others). Various forms of control can be imposed to the study procedures, in order to minimize the role of 'third variables'; the archetype of these procedures is the randomized double-blind controlled study (RCT). This practice is useful, necessary, and feasible in some PRM areas. But, as Table IC shows, for many reasons such designs can be impractical in behavioural research. Often a combination of experimental, non-experimental, and qualitative designs can provide a scientifically sound analysis of effectiveness in rehabilitation. For example, refined "quasi-experimental" research paradigms-stemming from psychological and social research are available, ${ }^{86}$ including single-case designs, time-series research designs, Small-N designs, and other special observational designs (e.g. the so-called practice-based evidence study designs). ${ }^{87}$ These designs may represent the right solution to research questions that cannot be stretched on an arbitrary standard to which exact conformity is forced (like in the myth of the Procustean bed), e.g. the RCT designs. Of course, the systematic reviews and associated methods of making practice recommendations need to be more sensitive to non-RCT evidence, in order to really identify and correctly grade best evidence for clinical practice. 82,88 For example, well-conducted cohort, correlational, or matching studies may give information that is more applicable to practice than explanatory RCTs with narrow inclusion criteria.

Clinical medicine (including PRM) Biomedicine

A) Variables

Behavioral; properties of the person as a whole (e.g. independence, fatigue, pain, balance, Properties of parts of the person (e.g. skin temperature, communication, etc.); often described by items in questionnaires, assessed by an observer arterial pressure, nerve conduction velocity, blood tests, (sometimes the subject himself).

"Latent". Not entirely or directly observable. Their quantity can only be inferred from CT scans, etc.) counts of behaviors representative of the subject's property (e.g. counts of responses to a Continuous, linear, measures. High precision and reliability questionnaire may indicate more or less independence in daily life, fatigue, pain, etc.).

"Measures" are ordinal, discrete (counts of events). Each response may be counted as 'one more', yet its "weight" is unknown. Heavy non-linearity and errors affect the sums of counts taken as proxies of the true "quantity". through instrumental measurement.

(To be continued) 


\section{COPYRIGHT $^{\circledR} 2018$ EDIZIONI MINERVA MEDICA}

SCIENCE AND RESEARCH IN PRM: SPECIFICITIES AND CHALLENGES EUROPEAN PHYSICAL AND REHABILITATION MEDICINE BODIES ALLIANCE

TABLE I.-(continues).

\begin{tabular}{|c|c|}
\hline \multicolumn{2}{|l|}{ B) Statistics } \\
\hline $\begin{array}{l}\text { Statistical models (e.g. Rasch analysis) is required to estimate linear measures and errors } \\
\text { from raw counts. } \\
\text { Uniqueness of the person. Averaging can be questionable. Error in individual measurement } \\
\text { cannot be considered as equal to the error estimated on means. } \\
\text { Individual peculiarities are substantive (e.g. in deciding treatment). } \\
\text { Outcomes are often discontinuous events (e.g. return to work, discharge home etc.). } \\
\text { Logistic regression and interaction-based modelling (e.g. survival analysis, neural } \\
\text { networks, Classification and Regression Trees) are more appropriate than conventional } \\
\text { ANOVA or regression statistics, based on 'main' effects from means. } \\
\text { Effect sizes moderate, sample sizes small, side effects moderate. Statistics should highlight } \\
\text { also power (enhancing the true positive risk). Significance just prevents false positive } \\
\text { findings but can conceal true positive findings not less than significance. } \\
\text { There is the need for estimating intrinsic precision of the instrument in order to evaluate } \\
\text { individual changes (minimal detectable change, minimal clinically important difference). }\end{array}$ & $\begin{array}{l}\text { Measurement units have established validity (e.g. units of } \\
\text { length, weight, voltage, time). } \\
\text { Means and medians are surrounded by errors lower that } \\
\text { individual measurements. Inferences can be made based } \\
\text { on established parameters (e.g. normal distribution, } \\
\text { confidence limits, etc.) } \\
\text { Outcomes are usually continuous or discrete (counts). } \\
\text { Established models applicable to means can be applied } \\
\text { to predictions (e.g. ANOVA, multiple regression) and } \\
\text { identification of 'latent' variables (e.g. factor analysis } \\
\text { procedures). } \\
\text { Size effects potentially large. Side effects potentially } \\
\text { harmful. Protection against false-positive findings } \\
\text { (significance) is usually prioritized. } \\
\text { Outcomes mostly given as changes at aggregate level, rather } \\
\text { than at individual level. }\end{array}$ \\
\hline \multicolumn{2}{|l|}{ C) Trial design } \\
\hline $\begin{array}{l}\text { The patient-clinician interaction has often to be taken as a source of efficacy, not of } \\
\text { measurement error. Effective randomization and blindness not always applicable. Quasi- } \\
\text { experimental designs often necessary. } \\
\text { Single-component, standard-dose treatments are rarely applicable. More and diverse } \\
\text { treatments are assigned to single individuals. Standard decision-trees (programs), not } \\
\text { standard treatments, must be developed. }\end{array}$ & $\begin{array}{l}\text { Research focus is on means/medians. Control by } \\
\text { randomization and blindness is usually applicable. } \\
\text { Single-component, standard-dose treatments are usually } \\
\text { applicable. }\end{array}$ \\
\hline
\end{tabular}

sponding to the holistic approach to patients, a holistic research concept, from basic research to meta-analysis has to be implemented reflecting the framework of PRM. As a major step the foundation of a Cochrane Rehabilitation field will give the opportunity not only to publish further reviews on important topics but also to implement the concept and values of PRM in the EBM community.

\section{Research training}

Most European trained young physicians have little or no formal training in research methodologies. Only a minority of the students is exposed to actual research projects during their studies, usually by chance. The situation is, however, improving slowly by faculties introducing a basic research component in the medical undergraduate, as well as postgraduate curriculum in many countries. This represents a window of opportunity for the Physical and Rehabilitation Medicine (PRM) discipline, since many students have a strong interest to participate in clinical projects as is the case in our area, and exposure to research is probably a strong motivating factor.

It is therefore recommendable that academic teach- ers and senior colleagues with an academic interest in PRM offer medical students a possibility to participate in a current rehabilitation project, involving them not only in data collection but also in helping to analyse the data and even developing a scientific text. It should be required that exposure to research training becomes a compulsory part of postgraduate PRM training. This may later lead to the possibility to recruit such junior co-workers to become PhD-students in Physical and Rehabilitation Medicine. From Sweden, we have had several such recent examples. ${ }^{103,104}$

However, vital to research training in PRM is to develop academic centers with sufficient sustainability and critical mass, to allow a continuing and vivid scientific dialogue and production. These centers should contain several permanent research positions, necessary laboratory functions and technical staff. They should always be linked to a clinical department to facilitate the interplay between practice and research and to make translational research possible. Currently, in Europe, the distribution of academic positions in PRM is very patchy, if one considers that 47 and 46 PRM chairs can be counted in France 105 and Italy, ${ }^{106}$ respectively, against one in Germany, and only a few in the UK. 


\section{COPYRIGHT $^{\circledR} 2018$ EDIZIONI MINERVA MEDICA}

The decrease in PRM academic capacity, together with the shortening in research personnel, equipment, space and technical support imposed to many public academic institutions by the financial crisis in European countries, represent a very severe threat to the provision of adequate PRM specialist education and training, as well as to the advance of rehabilitation research and evidence-based practice. Academic institutions and, even more, health organizations and national funding agencies, should invest to establish new rehabilitation research programs or strengthen ongoing ones, being aware of the key role played by rehabilitation towards the global improvement of population health, in a European society that is claimed to be inclusive, innovative and reflective. 107

Today, parts of the necessary infrastructure for research, such as access to a scientific library and to most scientific journals, can be solved through contact via the internet. It is also necessary to have regular discussions with experienced supervisors and this can also occur, at least partly, via the internet. This means that it is possible, as has been done in Denmark, to produce rehabilitation research 'over the surface' of a country rather than in one center. ${ }^{108}$ Such organizations may also carry the advantage to more easily permit multicenter studies, something that is often necessary in rehabilitation research due to the difficulty to recruit large homogenous patient groups.

To develop a reasonable quality of the research data to be produced, it is also necessary to provide more formal training of $\mathrm{PhD}$ students in research methodology. Such training is usually available at research-oriented medical faculties in the form of courses on statistics, ethics, study designs, library use and scientific writing.

Courses directed specifically to European $\mathrm{PhD}$ students in rehabilitation research have also been organized, usually in cooperation between two European universities. Such week-long courses not only allow rehabilitation $\mathrm{PhD}$ students from different European universities to meet and interact but they also give a basis for networking for future research. The structure of these courses has followed the International Classification of Functioning, Disability and Health 109 by WHO, with sections on methodology for impairment evaluation, ${ }^{110}$ for activity assessment and for participation assessment. The emphasis has been on controlled study designs, underlining the need of power calculations and the necessity of independent observers. Since many of the important instruments used in rehabilitation research produce ordinal data, an emphasis in the statistical part of the course has been on Rasch analysis and instruments that have undergone such analysis. ${ }^{111}$ All the PhD students participating in the courses have been asked to bring a poster on some of their own data and these posters have been discussed among the participants and the teachers in much appreciated poster sessions. It is hoped that these courses can be developed further to include specific subareas such as spinal cord injury rehabilitation research, traumatic brain injury-related research, stroke rehabilitation-related research and musculoskeletal rehabilitation research.

\section{Education to research}

As it is well known, physicians who practice also as academicians, have three paramount roles. First and foremost, they have to provide the best health care to their patients. Second, they need to train residents/ students and last but not least, they should conduct research. From one perspective, these three steps seem to align in decreasing order of importance. Herewith, in this era of evidence-based medicine, ${ }^{112}$ no physician is privileged to categorize him/herself as "expert" and bypass the necessity of research. Further, if one believes that he/she is treating his/her patients appropriately, they need first to prove it (research), convince others as well (peer-review) and then explain/share the "method" (scholarly publishing). This way, other colleagues will exploit the "method" and likely improve the efficacy of their interventions; yet we are physicians who are dealing with human beings.

Accordingly, the training of physiatrists must definitely be research-minded. This approach is also crucial for strengthening the "backbone" of physical and rehabilitation medicine. Concerning the potential threats to PRM specialty (e.g. lack of clear evidences as regards the efficacy of some rehabilitation procedures or certain overlaps with other musculoskeletal fields), we need to facilitate research. This can be readily done with countless assessment tools that are used by PRM physicians. These would include ultrasound imaging, isokinetic systems, electromyography, motor evoked potential recording, gait analysis or other technologies which sub- 


\section{COPYRIGHT $^{\circledR} 2018$ EDIZIONI MINERVA MEDICA}

stantially evaluate different parameters of structure and strength/function of the musculoskeletal system. ${ }^{113}$ It should be kept in mind that quantification means new data that may enlighten previously obscure questions.

In recent years, the increase in the number of research/publications in the realm of physical and rehabilitation medicine seems to be promising. ${ }^{114}, 115$ Herein, it is noteworthy that the broad spectrum of research areas -varying from the validation of assessment tools, to the definition of prognostic factors, to the establishment of novel rehabilitation techniques i.e. in the whole range of nervous and musculoskeletal diseases (e.g. stroke, spinal cord injury, osteoporosis, rheumatic diseases etc.)- is highly advantageous. ${ }^{75}$ Likewise, depending on the individual professional cults or interests and local conditions (clinical facility, patient population, etc.), PRM physicians conduct different studies that are also reflected to the scientific output. Importantly, when a relevant search is performed in Web of Science, PRM publications can be found to have fallen into different journal categories (e.g. clinical neurology, rheumatology, sport sciences, orthopedics) other than rehabilitation (Table IA). A similar search can also provide a snapshot as regards the top ranking countries (Table IB) and journals in the rehabilitation category (Table IC). Of note, during this search "rehabil* and med*" have been used as key words in the address section of Web of Science in order to avoid the exclusion of authors who addressed their affiliations without using the word "physical medicine" and also to avoid the primary inclusion of nonmedical health professionals working in rehabilitation sciences. Indisputably, this type of a search can only be used to have an overall idea -not for a precise in-depth analysis.

In conclusion, the amount of research in our field is mounting, and it seems to be faster than the number of pages available in rehabilitation journals.

\section{References}

1. Negrini S, Kiekens C, Levack W, Grubisic F, Gimigliano F, Ilieva E, et al. Cochrane physical and rehabilitation medicine: a new field to bridge between best evidence and the specific needs of our field of competence. Eur J Phys Rehabil Med. 2016 Jun;52(3):417-8.

2. Negrini S, Minozzi S, Taricco M, Ziliani V, Zaina F. A systematic review of physical and rehabilitation medicine topics as developed by the Cochrane Collaboration. Eur Medicophysica. 2007 Sep;43(3):381-90.
3. Cochrane Rehabilitation. Evidence [Internet]. 2017. Available from: http://rehabilitation.cochrane.org/evidence

4. Stucki G, Melvin J. The International Classification of Functioning, Disability and Health: a unifying model for the conceptual description of physical and rehabilitation medicine. J Rehabil Med. 2007 May;39(4):286-92.

5. Gutenbrunner C, Meyer T, Melvin J, Stucki G. Towards a conceptual description of Physical and Rehabilitation Medicine. J Rehabil Med. 2011 Sep;43(9):760-4.

6. Ceravolo MG. Curriculum for the Education of Specialists in Physical and Rehabilitation Medicine. White book on Physical and Rehabilitation Medicine in Europe. Chapter 9 of current $3^{\text {rd }}$ edition.

7. Stucki G, Grimby G. Organizing human functioning and rehabilitation research into distinct scientific fields. Part I: Developing a comprehensive structure from the cell to society. J Rehabil Med. 2007 May;39(4):293-8.

8. Stucki G, Reinhardt JD, Grimby G, Melvin J. Developing "Human Functioning and Rehabilitation Research" from the comprehensive perspective. J Rehabil Med. 2007 Nov;39(9):665-71.

9. Negrini S, Reinhardt JD, Stucki G, Giustini A. From Bruges to Venice 1: towards a common structure for international Physical and Rehabilitation Medicine Congresses. J Rehabil Med. 2009 Mar;41(4):297-8.

10. Gutenbrunner C, Reinhardt JD, Stucki G, Giustini A. From Bruges to Venice 2: towards a comprehensive abstract topic list for international Physical and Rehabilitation Medicine Congresses. J Rehabil Med. 2009 Mar;41(4):299-302.

11. Nugraha B, Paternostro-Sluga T, Schuhfried O, Stucki G, Franchignoni F, Abdul Latif L, et al.. Evaluation of the topic lists used in two world Congresses (2015 and 2016) in Physical and Rehabilitation Medicine. J Rehabil Med 2017;49:469-74

12. Stucki G, Cieza A, Melvin J. The International Classification of Functioning, Disability and Health (ICF): a unifying model for the conceptual description of the rehabilitation strategy. J Rehabil Med. 2007 May;39(4):279-85.

13. Reinhardt JD, Hofer P, Arenz S, Stucki G. Organizing human functioning and rehabilitation research into distinct scientific fields. Part III: Scientific journals. J Rehabil Med. 2007 May;39(4):308-22.

14. Stucki G, Giustini A. European Physical and Rehabilitation Medicine journals in concert: a European Society of Physical and Rehabilitation Medicine (ESPRM) initiative. Eur J Phys Rehabil Med. 2008 Sep;44(3):229-35.

15. Stucki G, Reinhardt JD, von Groote PM, DeLisa JA, Imamura M, Melvin JL. Chapter 2: ISPRM's way forward. J Rehabil Med. 2009 Sep;41(10):798-809.

16. Fineberg HV. Science and medicine in the 21st century: opportunities for rehabilitation medicine. Am J Phys Med Rehabil. 2005 Dec;84(12):928-31.

17. Frontera WR, Fuhrer MJ, Jette AM, Chan L, Cooper RA, Duncan PW, et al. Rehabilitation Medicine Summit: building research capacity. Am J Phys Med Rehabil. 2005 Dec;84(12):913-7.

18. Stucki G, Celio M. Developing human functioning and rehabilitation research. Part II: Interdisciplinary university centers and national and regional collaboration networks. J Rehabil Med. 2007 May;39(4):334-42.

19. Stucki G. Developing human functioning and rehabilitation research. Part I: Academic training programs. J Rehabil Med. 2007 May;39(4):323-33.

20. Negrini S, Kiekens C, Meerpohl JJ, Thomson D, Zampolini M, Christodoulou N, et al. Contributing to the growth of Physical and Rehabilitation Medicine (PRM): call for a Cochrane Field in PRM. Eur J Phys Rehabil Med. 2015 Jun;51(3):239-43.

21. Stucki G, Bickenbach J, Negrini S. Methodological notes on applying the International Classification of Functioning, Disability and Health in rehabilitation. Eur J Phys Rehabil Med. 2017 Feb;53(1):132-133.

22. Delarque A, Michail X, Christodoulou N. The action plan of the UEMS Physical and Rehabilitation Medicine Section and Board 2008-2010. Eur J Phys Rehabil Med. 2009 Jun;45(2):265-70.

23. Gutenbrunner C, Lemoine F, Yelnik A, Joseph P-A, de Korvin G, 


\section{COPYRIGHT $^{\odot} 2018$ EDIZIONI MINERVA MEDICA}

Neumann V, et al. The field of competence of the specialist in physical and rehabilitation medicine (PRM). Ann Phys Rehabil Med. 2011 Jul;54(5):298-318.

24. Sackett DL, Rosenberg WM, Gray JA, Haynes RB, Richardson WS. Evidence based medicine: what it is and what it isn't. BMJ. 1996 Jan 13;312(7023):71-2.

25. Prats M, Kerzoncuf M, Bensoussan L, Agresti J-P, Delorge B, Viton $\mathrm{J}-\mathrm{M}$, et al. A census of students with disabilities and the support provided at the University of Aix-Marseille. Int J Rehabil Res 2015 Sep;38(3):195-8.

26. Negrini S, Padua L, Kiekens C, Michail X, Boldrini P. Current research funding methods dumb down health care and rehabilitation for disabled people and aging population: a call for a change. Eur J Phys Rehabil Med. 2014 Dec;50(6):601-8.

27. European Commission - Research \& Innovation. H2020. National Contact Points [Internet]. Available from:

http://ec.europa.eu/research/participants/portal/desktop/en/support/national contact points.html

28. European Commission - Horizon 2020. Marie Sklodovska-Curie Actions (including Cofund schemes) [Internet]. Available from: https:// ec.europa.eu/programmes/horizon2020/ and http://ec.europa.eu/research/mariecurieactions/

29. European Commission. Euraxess. Researchers in Motion [Internet]. Available from: https://euraxess.ec.europa.eu/

30. Wings for Life [Internet]. Available from: http://www.wingsforlife. com/en/

31. Christopher and Dana Reeve Foundation - Research [Internet]. Available from: https://www.christopherreeve.org/research

32. Max-Planck-Gesellschaft. Max Planck Institutes [Internet]. Available from: https://www.mpg.de/institutes

33. Science Europe - Shaping the future of research. European Research Funding Organisations (RFO) and Research Performing Organisations (RPO) [Internet]. Available from: http://www.scienceeurope. org/

34. De Dominicis L, Pérez SE, Fernández-Zubieta A. European university funding and financial autonomy. A study on the degree of diversification of university budget and the share of competitive funding [Internet]. Available from: http://ftp.jrc.es/EURdoc/JRC63682.pdf

35. Groupe UGECAM. [Internet]. Available from: http://www.groupeugecam.fr/

36. Foundation Don Gnocchi. [Internet]. Available from: http://www. dongnocchi.it/

37. Council of Europe, COE. Additional protocol to the convention on Human Rights and Biomedicine, concerning biomedical research [Internet]. Available from: https://www.coe.int/en/web/conventions/ full-list/-/conventions/treaty/195

38. IASP International Association for the Study of Pain. IASP Guidelines for the Use of Animals in Research [Internet]. Available from: https:// www.iasp-pain.org/Education/Content.aspx?ItemNumber=1217

39. European Commission - Enviroment. Animals used for scientific purposes. Protection of animals in research [Internet]. Available from: http://ec.europa.eu/environment/chemicals/lab_animals/index en.htm

40. Dunn AG, Coiera E, Mandl KD, Bourgeois FT. Conflict of interest disclosure in biomedical research: A review of current practices, biases, and the role of public registries in improving transparency. Res Integr Peer Rev. 2016;1.

41. NCBI - Bookshelf. Conflict of Interest in Medical Research, Education, and Practice. Lo B, Field MJ, editors. Washington, DC: National Academies Press, 2009. Available from: https://www.ncbi. nlm.nih.gov/books/NBK22942/

42. Brænd AM, Straand J, Jakobsen RB, Klovning A. Publication and non-publication of drug trial results: a 10 -year cohort of trials in Norwegian general practice. BMJ Open. 2016 Apr 11;6(4):e010535.

43. Palazzo C, Ravaud J-F, Trinquart L, Dalichampt M, Ravaud P, Poiraudeau S. Respective contribution of chronic conditions to disability in France: results from the national Disability-Health Survey. PloS One. 2012;7(9):e44994.

44. Negrini S. Steady growth seen for research in physical and rehabili- tation medicine: where our specialty is now and where we are going. Eur J Phys Rehabil Med. 2012 Dec;48(4):543-8.

45. Mimouni M, Cismariu-Potash K, Ratmansky M, Shaklai S, Amir H, Mimouni-Bloch A. Trends in Physical Medicine and Rehabilitation Publications Over the Past 16 Years. Arch Phys Med Rehabil. 2016 Jun;97(6):1030-3.

46. Alam M, Rodrigues W, Pham BN, Thakor NV. Brain-machine interface facilitated neurorehabilitation via spinal stimulation after spinal cord injury: Recent progress and future perspectives. Brain Res. 2016 Sep 1;1646:25-33.

47. Stucki G. Olle Höök Lectureship 2015: The World Health Organization's paradigm shift and implementation of the International Classification of Functioning, Disability and Health in rehabilitation. J Rehabil Med. 2016 Jun 13;48(6):486-93.

48. Inserm. Institut National de la santé et de la recherche - French National Institute of Health and Medical Research [Internet]. Available from: http://english.inserm.fr/

49. Falkner S, Grade S, Dimou L, Conzelmann K-K, Bonhoeffer T, Götz $\mathrm{M}$, et al. Transplanted embryonic neurons integrate into adult neocortical circuits. Nature. 2016 10;539(7628):248-53.

50. Alliance for Biomedical Research in Europe [Internet]. Available from: https://www.biomedeurope.org/about/mission.html

51. Markram H, Muller E, Ramaswamy S, Reimann MW, Abdellah M, Sanchez CA, et al. Reconstruction and simulation of neocortical microcircuitry. Cell. 2015 Oct 8;163(2):456-92.

52. Palmero E, Palmero S, Murrell W. Brain tissue banking for stem cells for our future. Sci Rep. 2016 Dec 19;6:39394.

53. Brocard C, Plantier V, Boulenguez P, Liabeuf S, Bouhadfane M, Viallat-Lieutaud A, et al. Cleavage of $\mathrm{Na}(+)$ channels by calpain increases persistent $\mathrm{Na}(+)$ current and promotes spasticity after spinal cord injury. Nat Med. 2016 Apr;22(4):404-11.

54. Eatris. European infrastructure for translational medicine [Internet]. Available from: https://eatris.eu/

55. Contopoulos-Ioannidis DG, Ntzani E, Ioannidis JPA. Translation of highly promising basic science research into clinical applications. Am J Med. 2003 Apr 15;114(6):477-84.

56. Elley CR, Robertson MC, Garrett S, Kerse NM, McKinlay E, Lawton $\mathrm{B}$, et al. Effectiveness of a falls-and-fracture nurse coordinator to reduce falls: a randomized, controlled trial of at-risk older adults. J Am Geriatr Soc. 2008 Aug;56(8):1383-9.

57. Ramsay Health Care [Internet]. Available from: http://www.ramsayhealth.com/

58. INT. Institut de Neurosciences de la Timone [Internet]. Available from: http://www.int.univ-amu.fr/Institute

59. European Academy of Rehabilitation Medicine. Publications [Internet]. Available from: http://www.aemr.eu/index.php?option=com content $\&$ task $=$ category \&sectionid $=8 \& i d=19 \&$ Itemid $=44$

60. Physical and Rehabilitation Medicine Section and Board of the European Union of Medical Specialist. e-Learning [Internet]. Available from: http://www.euro-prm.org/index.php?lang=en

61. Evidence-Based Review of Stroke Rehabilitation, EBRSR [Internet]. Available from: http://www.ebrsr.com/

62. ESPRM. Calendar of scientific events [Internet]. Available from: http://www.esprm2018.com/ and http://www.esprm.net/meetings

63. European Society of Physical \& Rehabilitation Medicine. ESPRM committees/Evidence Based Medicine [Internet]. Available from: http://www.esprm.net/committees-details/FMiL/evidence-basedmedicine-ebm

64. European Journal of Physical and Rehabilitation Medicine [Internet]. Available from: http://www.ejprm.org/

65. Journal of Rehabilitation Medicine. Available from: www.medicaljournals.se/jrm/

66. Negrini S, Ilieva E, Moslavac S, Zampolini M, Giustini A. The European physical and rehabilitation medicine journal network: historical notes on national journals. Eur J Phys Rehabil Med. 2010 Jun;46(2):291-6.

67. Cochrane Rehabilitation [Internet]. Available from: http://rehabilitation.cochrane.org/

68. United Nations Human Rights - Office of the High Commissioner, 


\section{COPYRIGHT ${ }^{\odot} 2018$ EDIZIONI MINERVA MEDICA}

OHCHR. Committee on the Rights of Persons with Disabilities [Internet]. Available from: http://www.ohchr.org/EN/HRBodies/CRPD/ Pages/CRPDIndex.aspx

69. Bornmann L. Measuring the societal impact of research: research is less and less assessed on scientific impact alone--we should aim to quantify the increasingly important contributions of science to society. EMBO Rep. 2012 Aug;13(8):673-6.

70. Donadieu M, Le Fur Y, Lecocq A, Maudsley AA, Gherib S, Soulier $\mathrm{E}$, et al. Metabolic voxel-based analysis of the complete human brain using fast 3D-MRSI: Proof of concept in multiple sclerosis. J Magn Reson Imaging JMRI. 2016 Aug;44(2):411-9.

71. Hakim RM, Tunis BG, Ross MD. Rehabilitation robotics for the upper extremity: review with new directions for orthopaedic disorders. Disabil Rehabil Assist Technol. 2016 Dec 30;1-7.

72. Gama GL, Celestino ML, Barela JA, Forrester L, Whitall J, Barela AM. Effects of Gait Training With Body Weight Support on a Treadmill Versus Overground in Individuals With Stroke. Arch Phys Med Rehabil. 2017 Apr;98(4):738-45.

73. Young JM, Solomon MJ. How to critically appraise an article. Nat Clin Pract Gastroenterol Hepatol. 2009 Feb;6(2):82-91.

74. Lonsdale A, Sietsma Penington J, Rice T, Walker M, Dashnow H. Ten Simple Rules for a Bioinformatics Journal Club. PLoS Comput Biol. 2016 Jan;12(1):e1004526.

75. Ozçakar L, Franchignoni F, Negrini S, Frontera W. Writing a case report for the American Journal of Physical Medicine \& Rehabilitation and the European Journal of Physical and Rehabilitation Medicine. Am J Phys Med Rehabil. 2013 Feb;92(2):183-6.

76. Youtube. The University of Chicago : Communicating Science With Alan Alda [Internet]. Available from: https://www.youtube.com/ watch? $\mathrm{v}=$ DwjfMzwfuG8

77. Youtube. Alan Alda: The Art of Science Communication [Internet]. Available from: $\mathrm{https}: / / \mathrm{www}$. youtube.com/watch? $\mathrm{v}=\mathrm{UGo} 6 \mathrm{pTcTgVw}$

78. Vimeo. 2016 UQ 3MT (Three Minute Thesis) final winner\& people's choice - Anna-Liisa Sutt - "Dying to talk" [Internet]. Available from: https://vimeo.com/183241953

79. Ministère de l'Enseignement supérieur, de la Recherche et de l'Innovation. Etudiants handicapés. Contrats doctoraux handicap [Internet]. Available from: http://www.enseignementsup-recherche. gouv.fr/cid100602/contrats-doctoraux-handicap-campagne-nationale-2017.html

80. Tesio L. The good-hearted and the clever: clinical medicine at the bottom of the barrel of science. J Med Pers. 2010. J Med Pers. 2010 Dec;103-11.

81. Grimby G. Research and publishing in rehabilitation medicine. J Rehabil Med. 2009 Nov;41(13):1021-3.

82. Seel RT, Dijkers MP, Johnston MV. Developing and using evidence to improve rehabilitation practice. Arch Phys Med Rehabil. 2012 Aug;93(8 Suppl):S97-100.

83. Reinhard J, Stucki S. Organizing human functioning and rehabilitation research into distinct scientific fields revisited: Reply to the letters from Jensen \& Kartin and Graham \& Cameron. J Rehabil Med. 2009;204-206.

84. Borsboom D, Mellenbergh GJ, van Heerden J. The theoretical status of latent variables. Psychol Rev. 2003 Apr;110(2):203-19.

85. Tesio L. Measuring behaviours and perceptions: Rasch analysis as a tool for rehabilitation research. J Rehabil Med. 2003 May;35(3):10515.

86. Shadish WR, Cook TD, Campbell DT, Jr- I. Experimental and quasi experimental designs for generalized causal inference.

87. Horn SD, DeJong G, Deutscher D. Practice-based evidence research in rehabilitation: an alternative to randomized controlled trials and traditional observational studies. Arch Phys Med Rehabil. 2012 Aug;93(8 Suppl):S127-137.

88. Jette AM. Toward Systems Science in Rehabilitation. Phys Ther. 2016 Mar;96(3):270-1.

89. Tesio L, Franchignoni F. Don't touch the physical in "physical and rehabilitation medicine.” J Rehabil Med. 2007 Oct;39(8):662-3.

90. Alderson P. Absence of evidence is not evidence of absence. BMJ. 2004 Feb 28;328(7438):476-7.
91. Evidence-Based Medicine Working Group. Evidence-based medicine. A new approach to teaching the practice of medicine. JAMA. 1992 Nov 4;268(17):2420-5.

92. Verhagen AP, de Vet HC, de Bie RA, Kessels AG, Boers M, Bouter LM, et al. The Delphi list: a criteria list for quality assessment of randomized clinical trials for conducting systematic reviews developed by Delphi consensus. J Clin Epidemiol. 1998 Dec;51(12):1235-41.

93. Maher CG, Sherrington C, Herbert RD, Moseley AM, Elkins M. Reliability of the PEDro scale for rating quality of randomized controlled trials. Phys Ther. 2003 Aug;83(8):713-21.

94. de Morton NA. The PEDro scale is a valid measure of the methodological quality of clinical trials: a demographic study. Aust J Physiother. 2009;55(2):129-33.

95. Guyatt GH, Oxman AD, Vist GE, Kunz R, Falck-Ytter Y, AlonsoCoello P, et al. GRADE: an emerging consensus on rating quality of evidence and strength of recommendations. BMJ. $2008 \mathrm{Apr}$ 26;336(7650):924-6.

96. Schüneman H, Brożek J, Guyatt G, Oxman A. GRADE Handbook [Internet]. Available from: http://gdt.guidelinedevelopment.org/app/ handbook/handbook.html

97. Fregni F, Imamura M, Chien HF, Lew HL, Boggio P, Kaptchuk TJ, et al. Challenges and recommendations for placebo controls in randomized trials in physical and rehabilitation medicine: a report of the international placebo symposium working group. Am J Phys Med Rehabil. 2010 Feb;89(2):160-72.

98. Lexchin J, Bero LA, Djulbegovic B, Clark O. Pharmaceutical industry sponsorship and research outcome and quality: systematic review. BMJ. 2003 May 31;326(7400):1167-70.

99. Johnson MI, Paley CA, Howe TE, Sluka KA. Transcutaneous electrical nerve stimulation for acute pain. Cochrane Database Syst Rev. 2015 Jun 15;(6):CD006142.

100. Boutron I, Moher D, Altman DG, Schulz KF, Ravaud P, CONSORT Group. Extending the CONSORT statement to randomized trials of nonpharmacologic treatment: explanation and elaboration. Ann Intern Med. 2008 Feb 19;148(4):295-309.

101. Filipovic A, Kleinöder H, Dörmann U, Mester J. Electromyostimulation--a systematic review of the influence of training regimens and stimulation parameters on effectiveness in electromyostimulation training of selected strength parameters. J Strength Cond Res. 2011 Nov;25(11):3218-38

102. Garber CE, Blissmer B, Deschenes MR, Franklin BA, Lamonte MJ, Lee I-M, et al. American College of Sports Medicine position stand. Quantity and quality of exercise for developing and maintaining cardiorespiratory, musculoskeletal, and neuromotor fitness in apparently healthy adults: guidance for prescribing exercise. Med Sci Sports Exerc. $2011 \mathrm{Jul} ; 43(7): 1334-59$.

103. Persson AL, Westermark S, Merrick D, Sjölund BH. Validity of electrical stimulus magnitude matching in chronic pain. J Rehabil Med. 2009 Nov;41(11):898-903.

104. Brogårdh C, Johansson FW, Nygren F, Sjölund BH. Mode of hand training determines cortical reorganisation: a randomized controlled study in healthy adults. J Rehabil Med. 2010 Sep;42(8):789-94.

105. Ministère de l'Enseignement supérieur, de la Recherche et de l'Innovation. Les enseignants-chercherus des disciplines de santé. Effectifs hospitalo-universitaires des centres hospitaliers et universitaires [Internet]. 2015. Available from: http://www.enseignementsup-recherche.gouv.fr/cid23806/effectifs-hospitalo-universitairesdes-centres-hospitaliers-et-universitaires.htm106.

106. Cerca Università. Ricerca avanzata per docenti [Internet]. Available from: http://cercauniversita.cineca.it/php5/docenti/vis_docenti.php

107. Horizon 2020. Horizon 2020 projects - European Commission [Internet]. Available from: https://ec.europa.eu/programmes/horizon2020/en/h2020-sections-projects

108. Kjaersgaard A, Nielsen LH, Sjölund BH. Randomized trial of two swallowing assessment approaches in patients with acquired brain injury: Facial-Oral Tract Therapy versus Fibreoptic Endoscopic Evaluation of Swallowing. Clin Rehabil. 2014 Mar;28(3):243-53.

109. WHO. International Classification of Functioning, Disability and Health WHO Geneva 2001. 2001. 


\section{COPYRIGHT $^{\circledR} 2018$ EDIZIONI MINERVA MEDICA}

EUROPEAN PHYSICAL AND REHABILITATION MEDICINE BODIES ALLIANCE SCIENCE AND RESEARCH IN PRM: SPECIFICITIES AND CHALLENGES

110. Barat M, Franchignoni F. Assessment in physical medicine and rehabilitation views and perspectives. Maugeri Foundation Books. 2004.

111. Arsalis. Outcome application [Internet]. Available from: http://www. arsalis.com/outcome.html\#outcome-overview-en /

112. Franchignoni F, Ozçakar L, Michail X, Vanderstraeten G, Christodoulou N, Frischknecht R. Publishing in Physical and rehabilitation medicine. An update on the European point of view. Eur J Phys Rehabil Med. 2013 Oct;49(5):711-4.

113. Ulaşli AM, Kara M, Özçakar L. Publications of physical and rehabil- itation medicine physicians concerning musculoskeletal ultrasonography: an overview. J Rehabil Med. 2011 Jul;43(8):681-3.

114. Franchignoni F, Muñoz Lasa S, Ozçakar L, Ottonello M. Bibliometric indicators: a snapshot of the scientific productivity of leading European PRM researchers. Eur J Phys Rehabil Med. 2011 Sep;47(3):455-62.

115. Kara M, Ozçakar L, Kaymak B, Ozel S, Aknc A. Scientific publications in physical and rehabilitation medicine: a glance from Turkey. Am J Phys Med Rehabil. 2011 Jul;90(7):612-4.

For this paper, the collective authorship name of European PRM Bodies Alliance includes:

- European Academy of Rehabilitation Medicine (EARM)

- European Society of Physical and Rehabilitation Medicine (ESPRM)

- European Union of Medical Specialists PRM section (UEMS-PRM section)

- European College of Physical and Rehabilitation Medicine (ECPRM) - served by the UEMS-PRM Board

- the Editors of the $3^{\text {rd }}$ edition of the White Book of Physical and Rehabilitation Medicine in Europe: Alain DELARQUE; Pedro CANTISTA; Maria Gabriella CERAVOLO; Nicolas CHRISTODOULOU; Christoph GUTENBRUNNER; Carlotte KIEKENS; Saša MOSLAVAC; Enrique VARELA-DONOSO; Anthony B. WARD; Mauro ZAMPOLINI; Stefano NEGRINI

- the contributors: Catarina AGUIAR BRANCO; Kristian BORG; Frédéric BROCARD; Pedro CANTISTA; Maria Gabriella CERAVOLO; Alain DELARQUE; Franco FRANCHIGNONI; Walter FRONTERA; Francesca GIMIGLIANO; Gunnar GRIMBY; Christoph GUTENBRUNNER; Thierry LEJEUNE; Stefano NEGRINI; Diane PLAYFORD; Levent ÖZÇAKAR; Michael QUITTAN; João PÁSCOA PINHEIRO; Bengt H. SJÖLUND; Henk J. STAM; Katharina STIBRANT SUNNERHAGEN; Gerold STUCKI; Alan TENNANT; Luigi TESIO; André THEVENON; Stuart M. WEINSTEIN 


\section{COPYRIGHT $^{\circledR} 2018$ EDIZIONI MINERVA MEDICA}

\section{Appendix I.-Updated ISPRM Scientific Topic List}

Based on above described principle considerations and the evaluation of the use of the first proposal of the ISPRM topic list the following updated list has been derived (main changes underlined):

This proposal includes topics that are not mentioned in the first proposal and an improved systematic order of the topics.

\section{A. Clinical Physical and Rehabilitation Medicine Sciences}

Description: the clinical rehabilitation Sciences study how to provide best care with the goal of enabling people with health conditions experiencing or likely to experience disability to achieve and maintain optimal functioning in interaction with their immediate environment. It contains clinical research on best care including guidelines and standards, organization and quality management. No. A.1.-A.5. relate to specific health conditions; A.6. to A.11. to functioning issues and related rehabilitation goals

\section{A.1. Pain ${ }^{1}$}

A.1.1. Acute pain

A.1.2. Chronic generalized pain syndromes (including fibromyalgia)

A.1.3. Complex regional pain syndromes

A.1.4. Miscellaneous

A.2. Musculoskeletal conditions

A.2.1. Inflammatory joint diseases (e.g. rheumatoid arthritis, ankylosing spondylitis)

A.2.2. Degenerative joint diseases (e.g. osteoarthritis) ${ }^{2}$

A.2.3. Bone diseases (e.g. osteoporosis)

A.2.4. Local and regional pain syndromes of the neck and upper extremity (including enthesopathy, tendinitis and others)

A.2.5. Regional pain syndromes of the pelvis and lower extremity (including enthesopathy, tendinitis and others)

A.2.6. Back pain and spine disorders

A.2.7. Musculoskeletal trauma (e.g. fractures)

A.2.8. Sports injury

A.2.9. Miscellaneous

1 Pain can be classified both as a health condition and a body function.

2 Arthroplasty/joint replacement is classified under post-surgery rehabilitation.
A.3. Health conditions of the nervous system

A.3.1. Stroke

A.3.2. Traumatic brain injury

A.3.3. Spinal cord injury and other spinal cord diseases

A.3.4. Autoimmune and inflammatory neurological conditions (e.g. multiple sclerosis)

A.3.5. Neurodegenerative diseases (e.g. dementia)

A.3.6. Peripheral nerve injury

A.3.7. Vegetative states, minimally conscious and low awareness states

A.3.8. Miscellaneous

A.4. Mental health conditions

A.4.1. Anxiety, depression, bipolar disorders

A.4.2. Learning disabilities

A.4.3. Addiction disorder

A.4.4. Other mental health conditions

A.5. Internal medicine and related conditions

A.5.1. Heart and cardiovascular system

A.5.2. Diseases of the lymphatic system

A.5.3. Pulmonary diseases

A.5.4. Oro-laryngeal-pharyngeal diseases

A.5.5. Metabolic disorders (e.g. obesity, diabetes mellitus)

A.5.6. Cancer

A.5.7. Infectious diseases

A.5.8. Skin disorder and allergies

A.5.9. Bladder and bowel disorders

A.5.10. Uro-gynaecological disorders (incl. obstetric treatments)

A.5.11. Miscellaneous

A.6. Post-surgery and post-traumatic rehabilitation ${ }^{3}$

A.6.1. Musculoskeletal injury, bone fractures

A.6.2. Multiple trauma

A.6.3. Burn injury

A.6.4. Organ transplantation

A.6.5. Joint arthroplasty/joint replacement

A.6.6. Limb amputation

A.6.7. Miscellaneous

A.7. Rehabilitation for children and youth

A.7.1. Developmental disorders

A.7.2. Cerebral palsy

A.7.3. Spina bifida

A.7.4. Traumatic brain injury in children

3 Traumatic brain injury and spinal cord injury under conditions of the nervous system. 


\section{COPYRIGHT $^{\circledR} 2018$ EDIZIONI MINERVA MEDICA}

A.7.5. Juvenile rheumatoid arthritis

A.7.6. Infectious diseases in children and youth

A.7.7. Autism and other mental disorders in children (incl. Attention deficit disorder)

A.7.8. Miscellaneous

How about transitions of children with disabilities to adulthood?

A.8. Rehabilitation for people with old age 4

A.8.1. Dementia

A.8.2. Frailty

A.8.3. Sarcopenia

A.8.4. Depressive disorder in the elderly

A.8.5. risk of falls in the elderly

A.8.6. other geriatric conditions

A.9. Rehabilitation for Rare (orphan) diseases ${ }^{5}$

A.10. Rehabilitation addressing to specific functioning issues

A.10.1. Visual impairment and blindness

A.10.2. Auditory impairment and deaf

A.10.3. Speech and language dysfunction (including mute)

A.10.4. Sensory and motor control (including postural control)

A.10.5. Management of spasticity

A.10.6. Management of hemiplegia and paraplegia

A.10.7. Management of dysphagia

A.10.8. Respiratory impairment (incl. management of patients with artificial ventilation and weaning)

A.10.9. Malnutrition in rehabilitation

A.10.10. Sphincter dysfunction (including incontinence)

A.10.11. Management of wound and pressure sores

A.10.12. Management of fatigue and sleep disorders

A.10.13. Rehabilitation of disability-related mental dysfunction (e.g. depression, anxiety)

A.10.14. Sexual functioning in people with disability and chronic health conditions

A.10.15. Other specific functions

A.11. Sports rehabilitation (are you referring to the use of sports in rehabilitation? Sports injuries have been included in A.2.8)

A.12. Miscellaneous

4 This chapter also includes functioning issues.

5 Including case reports of specific rehabilitation issues.

\section{B. Biosciences in Rehabilitation}

Description: The Biosciences in rehabilitation are basic sciences that aim to explain body injury, adaptation and repair from the molecular to the cellular, organ system and organism level; and to identify targets for biomedical interventions to improve body functions and structures.

B.1. Mechanisms of tissue injury (e.g. inflammation, repetitive strain) and development of organ dysfunction (e.g. atrophy, spasticity, chronic pain)

B.2. Cell and tissue adaptation and mal-adaptation (e.g. plasticity, molecular mechanisms and mediators)

B.3. Autonomous regulation (incl. HPA-Axis, hormonal regulation systems)

B.4. Biological mechanism of interventions (e.g. pain relief, motor learning)

B.5. Miscellaneous

\section{Biomedical Rehabilitation Sciences and Engineering}

Description: the Biomedical rehabilitation sciences and engineering are applied sciences that study diagnostic measures and interventions including physical modalities suitable to minimize impairment, control symptoms and to optimize people's capacity.

C.1. Physical and rehabilitation Medicine (PRM) diagnostics (e.g. cardio-vascular functions and physical endurance, lung function testing, or imaging techniques) as related to organ systems and body functions (based on the first level of the International Classification of Functioning, Disability and Health (ICF) component body functions)

C.1.1. Diagnosis and assessment of mental functions (including neuropsychological assessment)

C.1.2. Diagnosis and assessment of sensory functions and pain

C.1.3. Diagnosis and assessment of voice and speech functions

C.1.4. Diagnosis and assessment of functions of the cardiovascular, haematological, immunological, and respiratory systems

C.1.5. Diagnosis and assessment of functions of the digestive, metabolic, and endocrine systems 


\section{COPYRIGHT $^{\circledR} 2018$ EDIZIONI MINERVA MEDICA}

C.1.6. Diagnosis and assessment of genitourinary and reproductive functions

C.1.7. Diagnosis and assessment of neurological, musculoskeletal and movement related functions (including gait analysis, posturography)

C.1.8. Diagnosis and assessment of functions of the skin and related structures

C.1.9. Assessment of health perception and quality of life

C.1.10. Miscellaneous

C.2. PRM interventions research

C.2.1. Exercise

C.2.2. Muscle training

C.2.3. Ergonomics

C.2.4. Joint mobilization and manipulation techniques

C.2.5. Prosthetics and orthotics

C.2.6. Massage and myofascial techniques

C.2.7. Vibration and other mechanical stimulation

C.2.8. Transcranial magnetic stimulation

C.2.9. Lymph therapy (manual lymphatic drainage)

C.2.10. Heat and cold

C.2.11. Hydrotherapy and balneotherapy

C.2.12. Light (including UV)

C.2.13. Climatotherapy

C.2.14. Electrotherapy (including functional electrophysiological stimulation)

C.2.15. Pharmacological interventions (e.g. for pain, spasticity, anti-inflammatory drugs)

C.2.16. Nerve root blockades and local infiltrations

C.2.17. Acupuncture and complementary and alternative therapies

C.2.18. Nutrition and diet

C.2.19. Virtual reality, exergaming

C.2.20. Rehabilitation technology, including implants, prosthesis, orthoses

C.2.21. Robots, aids and devices

C.2.22. Sports in rehabilitation

C.2.23. Injection techniques and infiltrations

C.2.24. Surgical interventions in rehabilitation

C.2.25. Miscellaneous

C.3. Comprehensive rehabilitation program (continuum of care research)

C.3.1. Acute and early post-acute rehabilitation programs

C.3.2. Post-acute rehabilitation programs

C.3.3. Long-term rehabilitation programs

C.3.4. Intermittent (boost) rehabilitation programs for chronic conditions

C.3.5. Programs for prevention of disability

\section{C.3.6. Miscellaneous}

C.4. Miscellaneous

\section{Integrative Rehabilitation Sciences}

Description: the Integrative rehabilitation sciences design and study rehabilitation systems, services, comprehensive assessments and intervention programmes, which integrate biomedical, personal factor and environmental approaches suited to optimize people's performance. This chapter includes the principles and contents of education and training of professionals in rehabilitation, as well as the evaluation of the rehabilitation team and multidisciplinary care.

D.1. Rehabilitation systems and services research

D.1.1. Health policy and law (including medical and social model of disability and rehabilitation)

D.1.2. Health strategies in Physical and Rehabilitation Medicine

D.1.3. Rehabilitation service organization

D.1.4. Rehabilitation economics

D.1.5. Community-based participation research

D.1.6. Miscellaneous

D.2. Comprehensive rehabilitation intervention research

D.2.1. Rehabilitation service evaluation (including acute, post-acute and community rehabilitation services)

D.2.2. Rehabilitation programme evaluation (e.g. homebased rehabilitation)

D.2.3. Rehabilitation technology assessment (e.g. telerehabilitation)

D.2.4. Rehabilitation strategies for specific issues (including rehabilitation strategies for developing countries and rehabilitation after natural disasters)

D.2.5. Technology transfer

D.2.6. Patient and proxy education

D.2.7. Miscellaneous

D.3. Social integration programmes and rehabilitation for specific socio-economic needs

D.3.1. Community based rehabilitation policy and management

D.3.2. Vocational rehabilitation

D.3.3. Support, assistance and independent living

D.3.4. Disability compensation

D.3.5. Miscellaneous 


\section{COPYRIGHT $^{\circledR} 2018$ EDIZIONI MINERVA MEDICA}

EUROPEAN PHYSICAL AND REHABILITATION MEDICINE BODIES ALLIANCE SCIENCE AND RESEARCH IN PRM: SPECIFICITIES AND CHALLENGES

D.4. Education and training in rehabilitation

D.4.1. Undergraduate medical education

D.4.2. Specialist training

D.4.3. Continuous medical education and professional development

D.4.4. Training in science and research

D.4.5. Training of other rehabilitation professionals

Training of patients and their families??

D.4.6. Miscellaneous

D.5. Rehabilitation management and administration

D.5.1. Rehabilitation service management (including integrated care and service concepts)

D.5.2. Case management

D.5.3. Structures and processes in rehabilitation institutions (maybe other health care institutions such as acute care hospitals?)

D.5.4. Miscellaneous

D.6. Miscellaneous

\section{E. Human Functioning Sciences}

Description: The human Functioning Sciences are basic sciences from the comprehensive perspective that aim to understand human functioning and to identify targets for comprehensive interventions.

E.1. Theories and models of functioning E.2. Classification of functioning (e.g. ICF core Sets; ICF up-date and revision)

E.3. Measurement of functioning (e.g. psychometrics of assessment tools; operationalization of ICF categories) E.4. Functioning epidemiology (population-based comparative studies of functioning across conditions, cultures, and time, e.g. on employment of people with disability)

E.5. Functioning impact assessment (e.g. prediction of the implications of policy and legislation on functioning)

E.6. Ethical issues and human rights (should this be a new section; maybe together with E.7?; Humanities and Rehabilitation?) good idea, I would do E6 and E7 together indeed

E.7. Cultural aspects of disability and rehabilitation (e.g. cultural influences, societal attitudes, religious beliefs) E.8. Miscellaneous 